\title{
Cardiac Dysfunction and Serum Ferritin Level as Early Prognostic Markers in Children with Sepsis: A Cross-sectional Study
}

\author{
Ahlam M. Ismail ${ }^{1}$, Mostafa Ahmed El Sayed Ahmed Abu Elela ${ }^{2}$, Islam Nashaat Roshdy Ahmed ${ }^{1}$ and \\ Nagwa Mohamed Sabry Mahmoud ${ }^{1, *}$ \\ ${ }^{1}$ Pediatric Department, Faculty of Medicine, Minia University, Egypt \\ ${ }^{2}$ Clinical Pathology Department, Faculty of Medicine, Minia University, Egypt \\ "Corresponding author: Pediatric Department, Faculty of Medicine, Minia University, Egypt. Email: dr_nagwa163@yahoo.com
}

Received 2021 May 12; Revised 2021 September 26; Accepted 2021 October 04.

\begin{abstract}
Background: Sepsis still causes morbidity and mortality in children admitted to the pediatric intensive care unit (PICU). Sepsis induces myocardial dysfunction and causes a reversible decline in ejection fraction (EF) of ventricles. Many biomarkers have been described for diagnosing sepsis, including serum ferritin and C-reactive protein (CRP).

Objectives: This study was conducted to assess the relationship of cardiac dysfunction evaluated using echocardiogram, ferritin, and CRP with negative outcomes of sepsis in the PICU.

Methods: A cross-sectional study was conducted on 80 patients aged between one month and six years who fulfilled the following criteria: (1) confirmed diagnosis of sepsis according to the American College of Critical Care Medicine; (2) receiving ventilation for $48 \mathrm{~h}$ and/or vasoactive medicines. The CRP and ferritin levels were recorded on the first day (D1) and third day (D3) of hospitalization in the PICU. Participants underwent an echocardiography study to investigate the ejection fraction on D1 and D3. All outcomes were evaluated.

Results: Our results showed a highly statistically significant difference between D1 and D3 in ejection fraction $(\mathrm{P}=0.001)$. The serum ferritin level and CRP enhanced significantly from D1 to D3 $(\mathrm{P}<0.001)$. Low left ventricular ejection fraction, and high serum ferritin were associated with unfavorable outcomes (P values $<0.001$ and 0.021 , respectively), but there was no significant difference in the outcomes regarding CRP.

Conclusions: Cardiac dysfunction and high serum ferritin were associated with unfavorable outcomes in children with sepsis admitted to the PICU.
\end{abstract}

Keywords: Sepsis, Echocardiogram, Ferritin, CRP, Children, Pediatric Intensive Care Unit

\section{Background}

Sepsis is a clinical syndrome that complicates severe infection. It is characterized by systemic inflammatory response syndrome (SIRS), immunological dysregulation, microcirculatory abnormalities, and end-organ dysfunction. The burden of sepsis among children hospitalized at the pediatric intensive care unit (PICU) is still high (1). Clinical presentations progress in severity from sepsis to severe sepsis, septic shock, and negative effects on several organs (2). Several diagnostic and biological markers have been studied to monitor the unfavorable evolution of sepsis in critically ill patients, but they are not established in developing countries (3-5). In pediatric sepsis, myocardial dysfunction may aggravate clinical deterioration, resulting in systolic or diastolic ventricular dysfunctions, leading to either shock or death $(6,7)$. Sepsis-induced myocardial dys- function (SIMD) has been defined as a reversible decline in ejection fraction (EF) of ventricles, dilatation of ventricles, and less response to fluid resuscitation and vasopressors (8). Nevertheless, the left ventricular ejection fraction (LVEF) is an index that depends on the load and represents the afterload and contractility of the left ventricular rather than the intrinsic contractile myocardial features. In septic shock, while the left ventricular intrinsic contractility is highly reduced, LVEF can be in the normal range if the afterload is seriously depressed (9).

Ferritin is a commonly distributed protein for iron storage that plays a role in the acute-phase response of infection. Ferritin causes an iron-deficient state by reducing the iron available in the serum, and this was thought of as a defensive mechanism for reducing the iron available to invading species (10). Systemic inflammatory response syndrome is triggered in critical diseases due to sepsis, and el- 
evated levels of pro-inflammatory cytokines are present in early disease phases. The pro-inflammatory cytokines promote the synthesis of ferritin and increase the serum ferritin levels (11).

Many biomarkers have been described for diagnosing sepsis, but currently, procalcitonin and C-reactive protein (CRP) are the only ones in routine clinical use (12). Inflammatory biomarkers, such as CRP, are helpful for the identification of considerable bacterial infections in children. Besides, CRP is one of the groups of IL-6-regulated acutephase reactant proteins and shows potential for determining the seriousness and prognosis of sepsis. A rapid decline in CRP rates in septic patients is associated with an appropriate response to primary antimicrobial treatment (13). Using echocardiography as a noninvasive tool is important for evaluating cardiac function in critically ill children and pediatric patients with sepsis $(14,15)$. The true clinical significance of cardiac dysfunction caused by sepsis and acute-phase reactants as ferritin and CRP and their relation to patients' outcomes are still uncertain.

\section{Objectives}

This study evaluated the LVEF as a measurement for cardiac dysfunction, serum ferritin, and CRP as acute-phase reactants and assessed their values as early prognostic markers for outcomes of pediatric sepsis in the PICU.

\section{Methods}

It is a cross-sectional study conducted in the PICU of the Department of Pediatrics, Minia Maternity and Children University Hospital, Egypt, from September 2019 to September 2020. After obtaining clearance from the Minia University Ethics Committee, Faculty of Medicine, written informed consent was signed by the parents or guardians of the children. The study included 80 cases diagnosed with sepsis who fulfilled the sepsis criteria (2). We considered SIRS in the presence of clinical or laboratory findings of infection. Hypothermia or hyperthermia, altered mental status, and abnormal capillary refill (either "flash" or > 2 seconds) were noted to identify children with septic shock. Other manifestations of organ dysfunction, including hypoxia and laboratory abnormalities, also often accompany the clinical signs of sepsis (2). According to the definition and clinical criteria of sepsis as life-threatening organ dysfunction caused by a dysregulated host response to infection and clinical operationalization, organ dysfunction can be represented by an increase in the sequential (sepsis-related) organ failure assessment (SOFA) score of two points or more. Our patients had a clinical diagnosis of sepsis, made by the presence of at least two of the following indicators: (1) tachycardia, (2) tachypnea, (3) temperature change, (4) leukocytosis, and (5) leukopenia for age in cases with confirmed or suspected infection, based on The Third International Consensus definitions for sepsis and septic shock (sepsis-3) (16). We recruited all cases diagnosed with sepsis, including those who were receiving ventilation for $48 \mathrm{~h}$ and/or vasoactive medicines. On the other hand, patients with congenital heart disease, confirmed or suspected endocrine disorder, congenital or acquired immunosuppression, and severe liver dysfunction were excluded from the study.

All the enrolled children underwent detailed historytaking and clinical examination. The patients' data, including age, gender, anthropometry, and admission disease category (respiratory, cardiovascular, gastrointestinal, neurological, and others) were recorded. Laboratory investigations included complete blood count (CBC), ESR, renal and liver function tests, serum glucose and electrolytes such as sodium $(\mathrm{Na})$, potassium $(\mathrm{K})$, calcium $(\mathrm{Ca})$, albumin, arterial blood gases, and blood culture and sensitivity. Serum ferritin and CRP levels were evaluated as acute-phase reactants. Other relevant investigations were required for selected cases, such as CSF examination, brain imaging as CT or MRI, and ECG. The pediatric risk of mortality score (PRISM) was calculated on admission to the PICU. The PRISM is a physiologically based scoring system used to quantify physiologic status, and when combined with other independent variables, it can compute the expected mortality risk and expected morbidity risk. These include changing the outcome to hospital survival/death for the first PICU admission only (17).

All patients received treatment according to the PICU protocol. Enrollment in the study did not change the normal treatment procedures. We followed participants until discharge or death. The patient prognosis was measured by the length of PICU stay, the need for and duration of mechanical ventilation support, and outcome at the end of the hospital stay.

The cardiac disorder evaluation was performed by transthoracic echocardiography to measure LVEF on the first and third days of hospitalization using the Logic v2 GE echo machine with 3 and $6 \mathrm{MHz}$ transducers. All echocardiography exams were conducted blindly by an equivalent pediatric cardiologist in our pediatric cardiology unit using the same device. Measurements were done from both long-axis and short-axis views, and the means calculated by the machine were recorded to avoid observer errors.

\subsection{Intervention}

The left ventricular end-diastolic dimension (LVEDD) was appraised at the maximum T-wave and the R-wave of 
the cardiac cycle. Hence, the left ventricular end-systolic dimension (LVESD) was calculated as FS (\%) = LVEDD - LVESD / LVEDD $\times 100$. The EF may be described as the percentage of blood the ventricle pumps out with each contraction, estimated as follows: EF (\%) = LVEDV - LVESV / LVEDV $\times 100$ (18).

Laboratory measurements: For this purpose, $4 \mathrm{~mL}$ of blood was drawn from each patient under complete aseptic conditions, $2 \mathrm{~mL}$ of which was added to a plain tube and incubated for $20 \mathrm{~min}$ at $37^{\circ} \mathrm{C}$. The tube was then centrifuged for $10 \mathrm{~min}$ at 3,000 rpm to separate the serum and stored at $-20^{\circ} \mathrm{C}$ till the day of analysis of ferritin and CRP on admission (D1) and $72 \mathrm{~h}$ after admission (D3).

\subsection{Serum Ferritin}

In our clinical laboratory, the standard range for the ferritin level is $10-250 \mathrm{ng} / \mathrm{mL}$, with variations based on age and sex. This number is given for orientation only; every laboratory should have its reference range. The quantitative test kit for ferritin uses a solid-phase enzyme combined with an immune sorbent assay. The assay uses one anti-ferritin antibody in the antibody-enzyme conjugate solution for solid phase (microtiter wells) immobilization, along with another mouse monoclonal anti-ferritin antibody. Then, CRP is estimated using the latex agglutination assay with the AVITEX CRP kit. The CRP latex test is a rapid agglutination procedure for direct detection and semi quantization of CRP on a slide. The principle of the test involves an immunological reaction between CRP (as an antigen), and the corresponding antibody fixed to the surface of latex particles. Thus, CRP in the sample reacts with IgG-coated polystyrene latex particles in the reagent, forming visible agglutination. The normal range for CRP levels in children in our clinical laboratory is up to $6 \mathrm{mg} / \mathrm{L}$ (19).

Statistical analysis: Data were analyzed using SPSS version 20.0 and MedCalc version 12.2.1. Data were described using median and interquartile range (IQR) for quantitative values. For categorical data, numbers and percentages were used. The Kolmogorov-Smirnov test was used to evaluate the normality of data, while the Mann-Whitney test was applied to compare independent groups, and the Wilcoxon test was used to compare dependent groups if data were non-parametric. The chi-square test or Fisher's exact test was applied for the comparison of categorical data. We also calculated the receiver operating characteristic (ROC) curve. Hence, the area under the curve was considered to assess the capability of both serum ferritin and ejection fraction to estimate the death rate. The ideal threshold was considered the value that was associated with the maximum area of the ROC curve. In addition, we applied the Spearman correlation to explain the relationship between the two parameters. Multiple binary logis- tic regressions were used to create a predictive model. A P value $<0.05$ was considered significant.

\section{Results}

Our study included 80 critically ill children with a diagnosis of sepsis. They were 32 (40.0\%) males, and 48 (60.0\%) females, and their ages ranged from one month to six years. The PRISM score on admission ranged from 5 to 25 with a mean \pm SD of $15.35 \pm$ 7.9. Patients' demographic, clinical, and laboratory data are shown in Table 1.

According to the findings of our study of 80 participants, Klebsiella was the most common Gram-negative organism isolated from blood culture causing sepsis (18.75\%), followed by S. haemolyticus (16.25\%). No culture growth was observed for 11 out of 80 children (13.75\%) (Appendix 1). The diagnoses among the study patients showed that 38 patients had pneumonia (47.5\%), 11 (13.75\%) had viral encephalitis, nine (11.25\%) had bacterial meningitis, 18 (20.0\%) had gastro-enteritis, and four (5.0\%) had sepsis with no specific focus of infection (Appendix 2).

In our study, we found that 38 out of 80 (47.5\%) patients had cardiac dysfunction ( $\mathrm{EF}<55 \%)$ and

most participants showed high levels of ferritin and CRP, with a mean of $535 \mathrm{ng} / \mathrm{mL}$ and $61.6 \mathrm{mg} / \mathrm{dL}$, respectively. In addition, as shown in Table 2, we found a considerable decline in serum ferritin and CRP on the third day of hospitalization $(\mathrm{P}<0.001)$. Also, we found a significant rise on the third day of hospitalization concerning $\mathrm{EF}(\mathrm{P}=0.001)$. Regarding the outcome, $48(60 \%)$ patients were non-survivors while 32 (40\%) were survivors. Besides, $\mathrm{EF} \%$ was significantly lower in those who died than in those who survived $(\mathrm{P}<0.001)$. In addition, the serum level of ferritin was significantly higher in those who died than in those who survived $(\mathrm{P}=0.021)$, but there was no significant difference in the outcome regarding CRP (Table 3 ). We found a significantly higher level of serum ferritin in cases suffering from cardiac dysfunction $(\mathrm{EF}<55 \%$ ) than their healthy counterparts ( $E F \geq 55 \%$, with a mean \pm SD of 625.6 \pm 214.3 and $490 \pm 216.2$, respectively, and a P-value of 0.029 (Appendix 3).

As shown in Table 4, the level of ferritin had a sensitivity and specificity of 62.5 and $81.2 \%$, respectively, concerning the estimation of death rate $(\mathrm{P}=0.002)$ with a threshold of $>550 \mathrm{ng} / \mathrm{mL}$, while for $\mathrm{EF}$, these values respectively were 83.3 and $87.5 \%(\mathrm{P}<0.001)$ with a threshold of $\leq 56 \%$.

In our study, there was a significant difference concerning the duration of mechanical ventilation $(h)(P=0.002)$, duration of inotropes $(\mathrm{h})(\mathrm{P}=0.008)$, and the highest inotropic value $(\mathrm{P}=0.004)$. Univariate and multivariable binary logistic regression models to predict the death rate are shown in (Table 5), which included parameters with 
Table 1. Socio-Demographic Characteristics and Laboratory Data of 80 Patients Studied on Admission ${ }^{\mathrm{a}}$

\begin{tabular}{|c|c|}
\hline Variables & Total $(\mathbf{n}=\mathbf{8 0})$ \\
\hline \multicolumn{2}{|l|}{ Age $(y)$} \\
\hline 1 month to 2 & $68(85)$ \\
\hline 2 to 6 & $12(15)$ \\
\hline \multicolumn{2}{|l|}{ Sex } \\
\hline Male & $32(40.0)$ \\
\hline Female & $48(60.0)$ \\
\hline \multicolumn{2}{|l|}{ Residence } \\
\hline Rural & $52(65)$ \\
\hline Urban & $28(35)$ \\
\hline Weight (kg) & $9.1 \pm 4.4(3.5-23)$ \\
\hline Length/height (cm) & $75.9 \pm 17.7(55-120)$ \\
\hline \multicolumn{2}{|l|}{ Consanguinity } \\
\hline+ ve & $24(30)$ \\
\hline - ve & $56(70)$ \\
\hline \multicolumn{2}{|c|}{ Family history of similar condition } \\
\hline+ ve & $18(22.5)$ \\
\hline - ve & $62(77.5)$ \\
\hline \multicolumn{2}{|l|}{ СBC } \\
\hline Hemoglobin (g/dL) & $9 \pm 1.5(8-10)$ \\
\hline $\operatorname{TLC}\left(\times 10^{9} / \mathrm{L}\right)$ & $16.8 \pm 9.3(9.5-23.5)$ \\
\hline Platelets $\left(\times 10^{9} / \mathrm{L}\right)$ & $222.6 \pm 174.9(82.5-310)$ \\
\hline \multicolumn{2}{|l|}{ Liver enzymes } \\
\hline ALT & $86.8 \pm 96.8(10-485)$ \\
\hline AST & $60.2 \pm 64.3(11-354)$ \\
\hline \multicolumn{2}{|l|}{ Kidney function tests } \\
\hline Urea $(\mathrm{mg} / \mathrm{dL})$ & $42.4 \pm 26.8(11-120)$ \\
\hline Creatinine $(\mathrm{mg} / \mathrm{dL})$ & $0.7 \pm 0.4(0.3-2)$ \\
\hline Prothrombin time (sec) & $16.8 \pm 3.7(11-25)$ \\
\hline Albumin (g/dL) & $3.6 \pm 0.6(2.5-5.5)$ \\
\hline \multicolumn{2}{|l|}{ Electrolytes } \\
\hline Sodium (mmol/L) & $142.7 \pm 10.9(125-168)$ \\
\hline Potassium (mmol/L) & $4.1 \pm 0.9(2.5-6.5)$ \\
\hline Calcium (mg/dL) & $8 \pm 1.8(5-10)$ \\
\hline $\mathrm{CRP}(\mathrm{mg} / \mathrm{dL})$ & $61.6 \pm 40.4(24-104)$ \\
\hline Ferritin $(\mathbf{n g} / \mathbf{m L})$ & $535 \pm 183.3(240-1150)$ \\
\hline
\end{tabular}

Abbreviations: SD, standard deviation; CRP, C-reactive protein; $\mathrm{CBC}$, complete blood count; TLC, total leucocyte count; AST, aspartate transaminase; ALT, alanine transaminase.

${ }^{a}$ Values are expressed as No. (\%) or mean $\pm \mathrm{SD}$ (range).

a significant association with death rate. According to the findings, two predictors of death included cardiac dysfunction and ferritin. Patients suffering from cardiac dysfunction were at a higher risk of death than their healthy counterparts $(\mathrm{P}=0.035)$. A rise in ferritin by 10 units was correlated with a $10 \%$ rise in the odd of infant death $(\mathrm{AOR}=$ $1.01,95 \% \mathrm{CI}=1.0-1.02$ ).

\section{Discussion}

Pediatric sepsis remains an important cause of PICU admission and mortality. Our research intended to evaluate the association between cardiac dysfunction, serum ferritin levels, and CRP as early prognostic markers of outcome in children with sepsis. We studied 80 infants and children diagnosed with sepsis caused by various factors hospitalized at the PICU. Pneumonia was the cause of sepsis in the majority of our patients (47.5\%), which is consistent with previous studies that mentioned the respiratory system with pneumonia (43\%) as a major infection site and concluded that chest infection was the most common clinical source of sepsis $(20,21)$.

Cardiac dysfunction is a major cause of clinical deterioration among children (7). In severe sepsis or septic shock, decreased LVEF is prevalent. Clinicians now have a better understanding of cardiac dysfunction caused by sepsis attributable to the use of bedside echocardiography in the ICU (22). The echocardiogram is used to manage those suffering from septic shock during volumetric resuscitation and is the ideal method of vasoactive drug evaluation (23, $24)$. Our results showed that $47.5 \%$ of the participants had cardiac dysfunction ( $\mathrm{EF}<55 \%$ ), which is higher than the values reported by previous similar studies, including $37 \%$ (6), 27\% (25), and 33\% (26). The difference in age and race may explain these discrepancies.

In our study, the mortality rate of severe sepsis was 60.0\%. We found that the median $\mathrm{EF} \%$ was considerably lower in non-survivors (44\%) than in survivors $(60 \%)(\mathrm{P}<$ 0.001). Another consecutive study investigated around 50 infants hospitalized at the PICU due to septic shock and reported a more declined EF\% in those who did not survive than in those who survived (27).

Although clinicians have a widely known understanding of sepsis-induced myocardial dysfunction, the association between left ventricular systolic dysfunction (LVSD) and the prognosis is still controversial $(26,28)$. It has been reported that LVSD is associated with septic shock mortality in adults $(29,30)$. Conversely, a meta-analysis showed that LVSD, defined as LVEF $<50 \%$, was not correlated with the prognosis of severe sepsis or septic shock in adults (31). Contrary to our results, other researchers concluded that myocardial dysfunction is highly prevalent in pediatric septic shock and is not associated with mortality, but 


\begin{tabular}{|c|c|c|c|c|}
\hline Values & D1 & D3 & Wilcoxon Test & P-Value $^{a}$ \\
\hline Ferritin (ng/mL) & & & -3.677 & $<0.001^{*}$ \\
\hline Median (IQR) & 522 & 400 & & \\
\hline Mean $\pm S D$ (range) & $535 \pm 183.3(240-1150)$ & $447.8 \pm 183.8(335.5-562)$ & & \\
\hline $\operatorname{CRP}(\mathrm{mg} / \mathrm{dL})$ & & & -3.648 & $<0.001^{*}$ \\
\hline Median (IQR) & 48 & 24 & & \\
\hline Mean $\pm S D$ (range) & $61.6 \pm 40.4(24-104)$ & $37.6 \pm 34(12-48)$ & & \\
\hline EF\% & & & -3.417 & $0.001^{*}$ \\
\hline Median (IQR) & 55 & 60 & & \\
\hline Mean $\pm S D$ (range) & $52.28 \pm 11.2(41.5-60)$ & $59.65 \pm 9.64(55-68.5)$ & & \\
\hline
\end{tabular}

Abbreviations: SD, standard deviation; CR, C-reactive protein.

${ }^{a} \mathrm{P}<0.05$ is significant and $\mathrm{P}<0.001$ is highly significant.

\begin{tabular}{|c|c|c|c|c|}
\hline \multirow{2}{*}{ Variables } & \multicolumn{2}{|c|}{ Outcome } & \multirow{2}{*}{ ZMWU } & \multirow{2}{*}{ P-Value } \\
\hline & $\begin{array}{c}\text { Non-survivors }(n=48) \\
(60.0 \%)\end{array}$ & Survivors $(n=32)(40.0 \%)$ & & \\
\hline Age group (y) & & & -3.207 & 0.032 \\
\hline 1 month to 2 & $40(50)$ & $28(35)$ & & \\
\hline 2 to 6 & $8(10)$ & $4(5)$ & & \\
\hline Sex & & & -4.205 & 0.168 \\
\hline Male & $19(23.75)$ & $13(16.25)$ & & \\
\hline Female & $25(31.25)$ & $23(28.75)$ & & \\
\hline Weight (kg) & $8.3 \pm 4.3(3.7-24)$ & $9.2 \pm 4.2(3.4-26)$ & -2.608 & 0.358 \\
\hline $\mathrm{CRP}(\mathrm{mg} / \mathrm{dL})$ & & & -3.401 & 0.188 \\
\hline Median (IQR) & 52 & 44 & & \\
\hline Mean $\pm S D$ (range) & $64.8 \pm 42.6(28-108)$ & $52.5 \pm 38.4(20-102)$ & & \\
\hline Ferritin & & & -2.30 & $0.021^{*}$ \\
\hline Median (IQR) & 565 & 456.5 & & \\
\hline Mean \pm SD (range) & $630.7 \pm 244.2(254-1150)$ & $440 \pm 122.4(240-650)$ & & \\
\hline $\mathbf{E F} \%$ & & & -4.106 & $<0.001^{*}$ \\
\hline Median (IQR) & 44 & 60 & & \\
\hline Mean $\pm S D$ (range) & $46.17 \pm 10.82(33-70)$ & $61.44 \pm 5.3(50-72)$ & & \\
\hline
\end{tabular}

Abbreviations: SD, standard deviation; ZMWU test, Z value of Mann-Whitney U test.

${ }^{a}$ Values are expressed as No. (\%) unless otherwise indicated.

${ }^{\mathrm{b}} \mathrm{P}<0.05$ is significant and $\mathrm{P}<0.001$ is highly significant.

Table 4. Serum Ferritin and Ejection Fraction (EF)\% as Predictors of Death

\begin{tabular}{lcccccc}
\hline Variables & Cut-off & AUC & Pvalue $^{\text {a }}$ & Sensitivity (\%) & Specificity (\%) & PPV (\%) \\
\hline Ferritin & $>550$ & 0.741 & $0.002^{*}$ & 62.5 & 81.2 & 83.3 \\
EF\% & $\leq 56$ & 0.887 & $<0.001^{*}$ & 83.3 & 87.5 & 90.9 \\
\hline
\end{tabular}

Abbreviations: AUC, area under the curve; PPV, positive predictive value; NPV, negative predictive value.

${ }^{a} \mathrm{P}<0.05$ is significant and $\mathrm{P}<0.001$ is highly significant. 


\begin{tabular}{|c|c|c|c|c|}
\hline \multirow{2}{*}{ Predictors } & \multicolumn{4}{|c|}{ Mortality } \\
\hline & Crude OR (95\% CI) & P-Value $^{a}$ & Adjusted OR(95\% CI) & P-Value $^{a}$ \\
\hline \multicolumn{5}{|l|}{$\mathbf{E F}$} \\
\hline No cardiac dysfunction & 1.00 (Reference) & & 1.00 (Reference) & \\
\hline Cardiac dysfunction & $45(4.86-416.5)$ & 0.001 & $63.22(1.35-2963)$ & $0.035^{*}$ \\
\hline Serum ferritin & $1.01(1.00-1.02)$ & 0.005 & $1.01(1.00-1.02)$ & $0.038^{*}$ \\
\hline CRP & $1.01(0.99-1.02)$ & 0.344 & - & - \\
\hline PRISM score & $2.14(0.20-22.7)$ & 0.526 & - & - \\
\hline Duration of MV (h) & $1.03(1.01-1.04)$ & 0.002 & $1.00(0.96-1.04)$ & 0.874 \\
\hline Duration of inotropes (h) & $1.03(1.01-1.05)$ & 0.008 & $0.99(0.95-1.03)$ & 0.538 \\
\hline Max. inotropic score & $1.03(1.01-1.06)$ & 0.004 & $1.00(0.95-1.05)$ & 0.924 \\
\hline
\end{tabular}

Abbreviations: MV, mechanical ventilator.

${ }^{\mathrm{a}} \mathrm{P}<0.05$ is significant and $\mathrm{P}<0.001$ is highly significant.

it is associated with higher severity of illness and the use of vasoactive drugs (32).

Most participants showed enhanced levels of ferritin and CRP that declined on the third day of hospitalization, so that we found a significant difference between the first day of admission (median $522 \mathrm{ng} / \mathrm{mL}$ ) and the third day (median $400 \mathrm{ng} / \mathrm{ml})(\mathrm{P}<0.001)$. Also, we found that the median ferritin level was significantly higher in those who died of sepsis $(565 \mathrm{ng} / \mathrm{mL})$ than in those who survived (456.5 ng/mL) $(\mathrm{P}=0.021)$. This comes in harmony with other researchers who concluded that ferritin was raised in children with sepsis and septic shock, and a higher ferritin level was associated with a poorer outcome in pediatric critical care patients (33-35). The median value of Creactive protein was higher on the first day of hospitalization (48 $\mathrm{mg} / \mathrm{L})$ than two days later (D3) $(24 \mathrm{mg} / \mathrm{L})$, and the difference was statistically significant $(\mathrm{P}<0.001)$, but there was no significant difference in the outcome regarding CRP. That comes in harmony with a similar study, which concluded that CRP alone or in combination with procalcitonin were not independent predictors of 28-day mortality in septic shock cases (36). On the other hand, in contrast to our findings, a previous study reported that the CRP level $>100 \mathrm{mg} / \mathrm{L}$ on admission was associated with an increased risk of mortality and prolonged length of stay (LOS) in survivors, and CRP may be a simple, early marker for prognosis in ICU admissions for sepsis (37). However, this study was a multicenter study with a large sample size conducted on 851 Swedish adult patients.

Based on our findings, the median value of serum ferritin level was considerably higher in those who were suffering from cardiac dysfunction $(\mathrm{EF}<55 \%)$ than their healthy counterparts ( $\mathrm{EF} \geq 55 \%$ ) with a mean \pm SD of 625.6 \pm 214.3 and $490 \pm 216.2$, respectively $(\mathrm{P}=0.029)$. Also, this is consistent with the study performed by Tonial et al., who reported that the mean serum ferritin level was considerably higher in those suffering from cardiac dysfunction than their healthy counterparts (38).

The ROC-AUC value of the ferritin level of $>550 \mathrm{ng} / \mathrm{mL}$ as the threshold was 0.741 , and it showed a sensitivity and specificity of 62.5 and $81.2 \%$, respectively. The parameters significantly correlated with death were cardiac dysfunction and serum ferritin. Those with cardiac dysfunction were at a higher risk of death than their healthy counterparts $(P=0.035)$, and a 10-unit increase in serum ferritin was correlated with a $10 \%$ increase in the odds of death ( $A O R=1.01,95 \% \mathrm{CI}=1.0-1.02$ ), which is consistent with the study by Garcia et al. (33) who reported that a ferritin level of $>500 \mathrm{ng} / \mathrm{ml}$ was correlated with an increased death rate.

\subsection{Limitations}

Some limitations of this study should be indicated. The first limitation is related to $\mathrm{EF} \%$ measurement by echocardiography, which is an operator-dependent assessment. Despite its limitation, this method was chosen because it is available in most PICU services in the Minia University Hospital. However, echocardiography was carried out by an expert, highly qualified pediatric cardiologist. The second limitation is the limited number of patients included in this study. Therefore, we recommend further studies on larger sample size.

\subsection{Conclusions}

Cardiac dysfunction estimated by an echocardiogram $(\mathrm{EF}<55 \%)$ and serum ferritin values $(\geq 500 \mathrm{ng} / \mathrm{mL})$ on the day of admission were significantly associated with unfavorable outcomes. Moreover, cardiac dysfunction can be 
applied as an early prognostic marker in pediatric cases with sepsis hospitalized at the PICU.

\section{Supplementary Material}

Supplementary material(s) is available here [To read supplementary materials, please refer to the journal website and open PDF/HTML].

\section{Acknowledgments}

We appreciate prof. Moustafa Mohamed Abdelraheem the professor of Pediatric Cardiology, Faculty of Medicine, Minia University, for his fruitful and helpful supervision, guidance, and support during this work.

\section{Footnotes}

Authors' Contribution: Study concept and design, Ahlam M. Ismail, Islam Nashaat Roshdy, and Nagwa Sabry; Analysis and interpretation of data, Islam Nashaat Roshdy; Drafting of the manuscript, Nagwa Sabry; Critical revision of the manuscript for important intellectual content, Nagwa Sabry; Statistical analysis, Islam Nashaat Roshdy; Laboratory data interpretation, Mostafa Abu Elela.

Conflict of Interests: We declare no conflict of interest with respect to this study.

Ethical Approval: This study was approved by the Ethics Committee, Faculty of Medicine, Minia University.

Funding/Support: We did not receive financial support for this study.

Informed Consent: Written informed consent was signed by the parents or guardians of the children.

\section{References}

1. Goldstein B, Giroir B, Randolph A; International Consensus Conference on Pediatric Sepsis. International pediatric sepsis consensus conference: definitions for sepsis and organ dysfunction in pediatrics. Pediatr Crit Care Med. 2005;6(1):2-8. doi 10.1097/01.PCC.0000149131.72248.E6. [PubMed: 15636651].

2. Davis AL, Carcillo JA, Aneja RK, Deymann AJ, Lin JC, Nguyen TC, et al. American College of Critical Care Medicine Clinical Practice Parameters for Hemodynamic Support of Pediatric and Neonatal Septic Shock. Crit Care Med. 2017;45(6):1061-93. doi: 10.1097/CCM.0000000000002425. [PubMed: 28509730].

3. Vila Perez D, Jordan I, Esteban E, Garcia-Soler P, Murga V, Bonil V, et al. Prognostic factors in pediatric sepsis study, from the Spanish Society of Pediatric Intensive Care. Pediatr Infect Dis J. 2014;33(2):152-7. doi: 10.1097/01.inf.0000435502.36996.72. [PubMed: 24413407].

4. Demirkol D, Yildizdas D, Bayrakci B, Karapinar B, Kendirli T, Koroglu TF, et al. Hyperferritinemia in the critically ill child with secondary hemophagocytic lymphohistiocytosis/sepsis/multiple organ dysfunction syndrome/macrophage activation syndrome: what is the treatment? Crit Care.2012;16(2):R52. doi: 10.1186/cc11256. [PubMed: 22715953]. [PubMed Central: PMC3681377].
5. Kaplan JM, Wong HR. Biomarker discovery and development in pediatric critical care medicine. Pediatr Crit Care Med. 2011;12(2):16573. doi: 10.1097/PCC.0b013e3181e28876. [PubMed: 20473243]. [PubMed Central: PMC2924462].

6. Raj S, Killinger JS, Gonzalez JA, Lopez L. Myocardial dysfunction in pediatric septic shock. J Pediatr. 2014;164(1):72-77 e2. doi: 10.1016/j.jpeds.2013.09.027. [PubMed: 24144393].

7. Smeding L, Plotz FB, Groeneveld AB, Kneyber MC. Structural changes of the heart during severe sepsis or septic shock. Shock. 2012;37(5):449-56. doi: 10.1097/SHK.0b013e31824c3238. [PubMed: 22301606].

8. Romero-Bermejo FJ, Ruiz-Bailen M, Gil-Cebrian J, Huertos-Ranchal MJ. Sepsis-induced cardiomyopathy. Curr Cardiol Rev. 2011;7(3):163-83. doi: 10.2174/157340311798220494. [PubMed: 22758615]. [PubMed Central: PMC3263481].

9. Repesse X, Charron C, Vieillard-Baron A. Evaluation of left ventricular systolic function revisited in septic shock. Crit Care. 2013;17(4):164. doi: 10.1186/cc12755. [PubMed: 23826739]. [PubMed Central: PMC3706940].

10. Bullen JJ, Rogers HJ, Spalding PB, Ward CG. Iron and infection: The heart of the matter. FEMS Immunol Med Microbiol. 2005;43(3):325-30. doi: 10.1016/j.femsim.2004.11.010. [PubMed:15708305].

11. Darveau M, Denault AY, Blais N, Notebaert E. Bench-to-bedside review: Iron metabolism in critically ill patients. Crit Care. 2004;8(5):35662. doi: 10.1186/cc2862. [PubMed: 15469598]. [PubMed Central: PMC1065005].

12. Sandquist M, Wong HR. Biomarkers of sepsis and their potential value in diagnosis, prognosis and treatment. Expert Rev Clin Immunol. 2014;10(10):1349-56. doi: 10.1586/1744666X.2014.949675. [PubMed: 25142036]. [PubMed Central: PMC4654927].

13. Cho SY, Choi JH. Biomarkers of sepsis. Infect Chemother. 2014;46(1):112. doi: 10.3947/ic.2014.46.1.1. [PubMed: 24693464]. [PubMed Central: PMC3970312].

14. Abdalaziz FA, Algebaly HAF, Ismail RI, El-Sherbini SA, Behairy A. The use of bedside echocardiography for measuring cardiac index and systemic vascular resistance in pediatric patients with septic shock. Rev Bras Ter Intensiva. 2018;30(4):460-70. doi: 10.5935/0103-507X.20180067. [PubMed: 30672970]. [PubMed Central: PMC6334480].

15. Spenceley N, MacLaren G, Kissoon N, Macrae DJ. Monitoring in pediatric cardiac critical care: A worldwide perspective. Pediatr Crit Care Med. 2011;12(4 Suppl):S76-80. doi: 10.1097/PCC.0b013e3182211d66. [PubMed: 22129555].

16. Singer M, Deutschman CS, Seymour CW, Shankar-Hari M, Annane $\mathrm{D}$, Bauer $\mathrm{M}$, et al. The Third International Consensus Definitions for Sepsis and Septic Shock (Sepsis-3). JAMA. 2016;315(8):801-10. doi: 10.1001/jama.2016.0287. [PubMed: 26903338]. [PubMed Central: PMC4968574].

17. Pollack MM, Holubkov R, Funai T, Dean JM, Berger JT, Wessel DL, et al. The Pediatric Risk of Mortality Score: Update 2015. Pediatr Crit Care Med. 2016;17(1):2-9. doi: 10.1097/PCC.0000000000000558. [PubMed: 26492059]. [PubMed Central: PMC5048467].

18. Lang RM, Bierig M, Devereux RB, Flachskampf FA, Foster E, Pellikka PA, et al. Recommendations for chamber quantification. Eur J Echocardiogr. 2006;7(2):79-108. doi: 10.1016/j.euje.2005.12.014. [PubMed: 16458610].

19. Ogirala T. Design and implementation of an image based portable ELISA analyzer using EIPA and 4PLR [master's thesis]. Burnaby, Canada: Simon Fraser University; 2017.

20. Weiss SL, Fitzgerald JC, Balamuth F, Alpern ER, Lavelle J, Chilutti M, et al. Delayed antimicrobial therapy increases mortality and organ dysfunction duration in pediatric sepsis. Crit Care Med. 2014;42(11):240917. doi: 10.1097/CCM.0000000000000509. [PubMed: 25148597]. [PubMed Central: PMC4213742]. 
21. El-Kinany HA, Mahfouz AA, Abd El-Fattah LE. Impact of pre-pediatric ICU management on prognosis of sepsis and septic shock at Alexandria University Children's Hospital. Alex J Pediatrics. 2018;31(1):14.

22. Sato R, Nasu M. A review of sepsis-induced cardiomyopathy. Intensive Care. 2015;3:48. doi: 10.1186/s40560-015-0112-5. [PubMed: 26566443]. [PubMed Central: PMC4642671].

23. Ranjit S, Kissoon N. Bedside echocardiography is useful in assessing children with fluid and inotrope resistant septic shock. Indian J Crit Care Med. 2013;17(4):224-30. doi: 10.4103/0972-5229.118426. [PubMed: 24133330]. [PubMed Central: PMC3796901].

24. Carmona F, Manso PH, Silveira VS, Cunha FQ, de Castro M, Carlotti AP. Inflammation, myocardial dysfunction, and mortality in children with septic shock: an observational study. Pediatr Cardiol. 2014;35(3):463-70. doi: 10.1007/s00246-013-0801-6. [PubMed: 24091885]. [PubMed Central: PMC7100657].

25. Pulido JN, Afessa B, Masaki M, Yuasa T, Gillespie S, Herasevich $\mathrm{V}$, et al. Clinical spectrum, frequency, and significance of myocardial dysfunction in severe sepsis and septic shock. Mayo Clin Proc. 2012;87(7):620-8. doi: 10.1016/j.mayocp.2012.01.018. [PubMed: 22683055]. [PubMed Central: PMC3538477].

26. Furian T, Aguiar C, Prado K, Ribeiro RV, Becker L, Martinelli N, et al. Ventricular dysfunction and dilation in severe sepsis and septic shock: Relation to endothelial function and mortality. J Crit Care. 2012;27(3):319 e9-15. doi: 10.1016/j.jcrc.2011.06.017. [PubMed: 21855287].

27. Elgazzar BA, Hassan FM, Khattab AA, Elzayat RS. E/A ratio and troponin I level as measures of mortality in patients with shock in pediatric intensive care units. Menoufia Med J. 2018;31(2):677.

28. Vieillard-Baron A, Caille V, Charron C, Belliard G, Page B, Jardin F. Actual incidence of global left ventricular hypokinesia in adult septic shock. Crit Care Med. 2008;36(6):1701-6. doi: 10.1097/CCM.0b013e318174db05. [PubMed:18496368].

29. Prabhu MM, Yalakala SK, Shetty R, Thakkar A, Sitapara T. Prognosis of left ventricular systolic dysfunction in septic shock patients. $J$ Clin Diagn Res. 2015;9(3):OC05-8. doi: 10.7860/JCDR/2015/10812.5640. [PubMed: 25954646]. [PubMed Central: PMC4413095].

30. Weng L, Liu YT, Du B, Zhou JF, Guo XX, Peng JM, et al. The prognostic value of left ventricular systolic function measured by tissue Doppler imaging in septic shock. Crit Care. 2012;16(3):R71. doi: 10.1186/cc11328.
[PubMed: 22554063]. [PubMed Central: PMC3580613].

31. Sevilla Berrios RA, O'Horo JC, Velagapudi V, Pulido JN. Correlation of left ventricular systolic dysfunction determined by low ejection fraction and 30-day mortality in patients with severe sepsis and septic shock: A systematic review and meta-analysis. J Crit Care. 2014;29(4):495-9. doi: 10.1016/j.jcrc.2014.03.007. [PubMed: 24746109].

32. Williams FZ, Sachdeva R, Travers CD, Walson KH, Hebbar KB. Characterization of Myocardial Dysfunction in Fluid- and CatecholamineRefractory Pediatric Septic Shock and Its Clinical Significance. J Intensive Care Med. 2019;34(1):17-25. doi: 10.1177/0885066616685247. [PubMed: 28030994].

33. Garcia PC, Longhi F, Branco RG, Piva JP, Lacks D, Tasker RC. Ferritin levels in children with severe sepsis and septic shock. Acta Paediatr. 2007;96(12):1829-31. doi: 10.1111/j.1651-2227.2007.00564.x. [PubMed: 18001337].

34. Awasthi PR, Angurana SK. Ferritin Levels in Children With Sepsis in Low-Middle Income Countries: Do We Need Lower Threshold? Pediatr Crit Care Med.2020;21(10):923. doi: 10.1097/PCC.0000000000002443. [PubMed: 33009312].

35. Bennett TD, Hayward KN, Farris RW, Ringold S, Wallace CA, Brogan TV. Very high serum ferritin levels are associated with increased mortality and critical care in pediatric patients. Pediatr Crit Care Med. 2011;12(6):e233-6. doi: 10.1097/PCC.0b013e31820abca8. [PubMed: 21263363].

36. Ryoo SM, Han KS, Ahn S, Shin TG, Hwang SY, Chung SP, et al. The usefulness of C-reactive protein and procalcitonin to predict prognosis in septic shock patients: A multicenter prospective registry-based observational study. Sci Rep. 2019;9(1):6579. doi: 10.1038/s41598-01942972-7. [PubMed: 31036824]. [PubMed Central: PMC6488613].

37. Koozi H, Lengquist M, Frigyesi A. C-reactive protein as a prognostic factor in intensive care admissions for sepsis: A Swedish multicenter study. J Crit Care. 2020;56:73-9. doi: 10.1016/j.jcrc.2019.12.009. [PubMed: 31855709].

38. Tonial CT, Garcia PCR, Schweitzer LC, Costa CAD, Bruno F, Fiori $\mathrm{HH}$, et al. Cardiac dysfunction and ferritin as early markers of severity in pediatric sepsis. J Pediatr (Rio J). 2017;93(3):301-7. doi: 10.1016/j.jped.2016.08.006. [PubMed: 28126563]. 